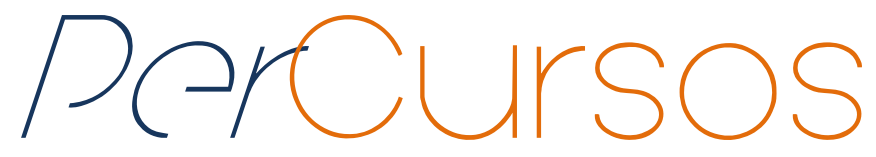

\title{
Cartografia, mapa e fotografia: outra narrativa das serras turísticas capixabas no contexto da educação geográfica do IFES
}

\begin{abstract}
Resumo
A ideia de cartografia e mapas, neste estudo, vai além dos conceitos consagrados pela Geografia e que estão materializados pelos manuais e pelos livros didáticos que povoam as escolas da Educação Básica, especificamente no Instituto Federal de Educação do Espírito Santo (IFES). A cartografia é concebida neste trabalho como o acompanhamento de processos criativos em devir e os mapas como as relações entre os sujeitos com os acontecimentos que constituem os espaços dentro de uma perspectiva política, usando como referências teóricas a "Filosofia da diferença" de Gilles Deleuze e Félix Guattari. O presente estudo é o resultado da cartografia de um experimento artístico (Oficina), "Portfólio de Imagens da minha Cidade", realizado durante o cotidiano das aulas de Geografia ao longo do ano de 2016. Resultados demonstraram que é possível mobilizar outros pensamentos sobre espaço e lugar, mesmo dentro de um ambiente marcado por processos de subjetivação que padronizam a visão dos estudantes sobre um meio marcado por apelos turísticos. Os processos criativos foram provocados pela arte e fizeram os estudantes transcenderem os livros didáticos, os atlas, os globos terrestres, bem como as imagens veiculadas massivamente pelos meios de comunicações locais.
\end{abstract}

\section{Ernandes de Oliveira Pereira}

Mestre em Geografia pela Univ.

Federal do Espírito Santo - UFES.

Doutorando em Geografia na

Universidade Federal do Espírito Santo - UFES.

Membro do Grupo de Pesquisa "Política Espacial das Imagens e Cartografias" da UFES.

Professor do Instituto Federal de Educação, Ciência e Tecnologia do Espírito Santo - IFES.

Brasil

ernandes.pereira@ifes.edu.br

Palavras-chave: Cartografia. Mapas. Educação Geográfica. Narrativas Alternativas. Fotografia.

\section{Para citar este artigo:}

PEREIRA, Ernandes de Oliveira. Cartografia, mapa e fotografia: outra narrativa das serras turísticas capixabas no contexto da educação geográfica do IFES. Revista PerCursos, Florianópolis, v. 19, n.41, p. 234 -257, set./dez. 2018.

\section{DOI: $10.5965 / 1984724619412018234$}

http://dx.doi.org/10.5965/1984724619412018234 


\title{
Cartography, map and photography: another narrative of the sierras of the capixabas in the context of the geographical education of the IFES
}

\begin{abstract}
The idea of cartography and maps, in this study, goes beyond the consecrated concepts by Geography that are materialized by textbooks used in Basic Education schools, specifically, in the Federal Institute of Education of Espírito Santo (IFES). Cartography is conceived in this work as the accompaniment of creative processes, while the maps are comprehended as the relations between the people and the events that constitute the spaces within a political perspective, using as theoretical references the "Philosophy of the difference" of Gilles Deleuze and Félix Guattari. The present study is the result of the cartography of an artistic experiment (Workshop), "Portfolio of Images of My City", carried out during Geography classes throughout the year 2016. Results showed that it is possible to mobilize other thoughts about space and place, even within an environment marked by processes of subjectivities that standardize students' views on a situation marked by tourist appeals. Creative processes were brought about by art and made students transcend textbooks, atlases, terrestrial globes, as well as images that are massively broadcasted by local media.
\end{abstract}

Keywords: Cartography. Maps. Geographic Education. Alternative Narratives. Photography. 


\section{A noção geográfica de espaço, lugar, cartografia, mapas e suas} reverberações sobre os processos metodológico-científicos adotados nesta pesquisa

As noções de espaço e lugar não são consideradas aqui como superfícies ou suportes em que todos os fenômenos naturais e humanos acontecem. Pensar o espaço e o lugar como superfícies, onde tudo se localiza, faz parte de um discurso político que pretende controlar o desafio da espacialidade (MASSEY, 2015). Uma espécie de aprisionamento dessas noções em parâmetros normativos que na atualidade seguem os princípios econômicos vigentes. A ideia de propriedade privada, por exemplo, consolidase como o elemento mais sagrado da atualidade. Ela é inviolável, pois é protegida pelos mecanismos legais e explorada pelos processos especulativos inerentes ao sistema econômico atual. Essa ideia de espaço, a partir desse ponto de vista - como superfície que deve ser controlada e protegida - impregnou os livros didáticos, os manuais escolares e a noção de cartografia e mapas.

A noção de lugar também é afetada por uma perspectiva que o considera como "algo fechado, coerente, integrado, como autêntico, como 'lar', um refúgio seguro" (MASSEY, 2015, p. 25). O lugar como superfície que abriga uma "identidade" única, quase eterna e vista como essência. Lugar em que não cabem outras possíveis histórias, outras narrativas, outras culturas. Derivam dessa forma de pensar expressões como "esse é o meu lugar”, "precisamos defender o nosso lugar". De quem? Dos estrangeiros? Dos imigrantes? Dos refugiados? Não seria reduzir demais essa noção?

Portanto, a noção de espaço que ancora esta pesquisa é fruto das inter-relações entre pessoas, sistemas e natureza em todas as escalas simultaneamente; como campo de possibilidades que permita a coexistência de múltiplas trajetórias, narrativas, histórias, estórias; como algo sempre em fase de construção, nunca acabado e delimitado (MASSEY, 2015). Dessa forma, o lugar é concebido como uma coleção dessas trajetórias que se cruzam, que se transpassam sem imobilizarem-se; sempre provocando outros movimentos outras trajetórias; não só de encontros e conexões, mas também de 
desencontros e desconexões de todas as relações entre pessoas, sistemas e natureza (MASSEY, 2015).

A escolha dessas noções - em permanente devir - de espaço e lugar reverbera sobre as metodologias que foram construídas ao longo desta pesquisa. Ora como “medir”, "conceituar”, “controlar as variáveis” de um espaço e lugar tão fluidos como os cubos de gelo de Bauman (2001): que se derretem e se misturam ao meio em que estão inseridos, de modo que os limites entre o gelo e a água (espaço e lugar) tornam-se imperceptíveis (BAUMAN, 2001)? Nesse caso, talvez o importante seja compreender os processos políticos e cognitivos que constituem esse espaço e esse lugar. Nesse sentido, a metodologia adotada aproxima-se mais à cartografia como acompanhamento desses processos (BARROS; KASTRUP, 2015) políticos e cognitivos que interferem na constituição do pensamento sobre o espaço e lugar. O que interessa é saber como se dá o movimento de pensar sobre o espaço e lugar.

Essa perspectiva de cartografia afasta-se daquela apresentada pelos manuais e livros didáticos: como um conjunto de técnicas que constituem uma "linguagem exclusivamente visual e submetida às leis fisiológicas da percepção das imagens" (JOLY, 2007, p. 13); ou como uma linguagem que "estrutura-se em símbolos e signos, e é compreendida como um produto da comunicação visual que dissemina informação espacial” (CASTELLAR, 2011, p. 125); ou como "conjunto de técnicas e conhecimentos científicos que resultam na representação do espaço por meio de mapas, cartas, croquis, esboço, etc." (ADÃO; FURQUIM JR.; 2013, p. 38). Essas são definições válidas e consagradas para a comunidade científica, entretanto, a ideia de cartografia, presente neste estudo, vai além da perspectiva gráfica e visual. O que se quer cartografar são os movimentos e fluxos contínuos do pensamento sobre o espaço e lugar, dentro de uma dimensão cognitiva e principalmente abstrata. O resultado dessa metodologia, que é chamada aqui de cartografia, não se resume a um mapa mental gráfico (desenhos, esboços e cartas) e sim à descrição dos processos que desencadeiam e movimentam o pensamento dos estudantes sobre o espaço. Nesse sentido, os mapas podem ser gráficos, mas também comportamentais, orais, e podem se deslocar entre os limites da arte, da ciência e da filosofia. 
Partindo desse pressuposto de que o espaço e o lugar estão sempre em processo de mudança, em permanente devir, os mapas nunca estarão concluídos, porque também sofrerão mudanças a partir dos fluxos da desterritorialização (política e cognição), num constante processo de des(re)territorialização (GIRARDI, 2012), cuja ideia de território se afasta daquela dos livros didáticos -- delimitado por fronteiras físicas e políticas, por exemplo. Isso posto, trata-se do território que é fruto da dimensão do pensamento e da imaginação, no qual não há hierarquias, não há categorização, não há definições eternas sobre alguma coisa. Nesse contexto, as (des)(re)territorizalizações correspondem mais aos fluxos das funções (das ciências), dos conceitos (filosóficos), dos afectos e dos perceptos (das artes) que se movem incessantemente; constituindo rizomas, cujas cadeias semióticas podem ser (des)(re)conectadas em qualquer ponto, porque não possuem centralidade, não possuem uma raiz principal que conduz o processo de criação (DELEUZE; GUATTARI, 2011). Rizomas que podem ser rompidos de qualquer lugar, por linhas de segmentaridade que explodem em linhas de fuga e que remetem a outras (DELEUZE; GUATTARI, 2011).

A partir dessas premissas, a cartografia passa a ser constituída por um conjunto de procedimentos metodológicos que acompanham esses processos de (des)(re)territorializações de pensamentos sobre o espaço e o lugar. O que interessa são as relações entre as artes, a ciência e a filosofia, sem que nenhuma delas tenha privilégio sobre a outra, porque cada uma é em si potência de criação (DELEUZE, 2013). Nenhuma é melhor ou mais importante do que a outra. É a partir desse pensamento sobre espaço, lugar, cartografia e mapa, que a linguagem fotográfica e seus signos artísticos, encontram importância como grandes mobilizadores do pensamento dos estudantes sobre o espaço e o lugar. Tudo é emissor de signos. Tudo pode ser submetido ao processo de aprendizagem.

Além disso, os níveis de interpretação dos signos podem ser ultrapassados. Linhas de fugas podem originar-se e outros sistemas de signos podem ser acessados pelo aprendiz. "É por esta razão que todos os signos convergem para a arte [...]. O essencial está nos signos da arte" (DELEUZE, 1987, p. 14). Com isso, os estudantes são forçados a entender o mundo que os cerca, compreender as pessoas, as lógicas que orientam as 
circunstâncias com que eles se deparam ao acaso. Nessa forma de ver, a atitude de “aprender diz respeito essencialmente aos signos” (DELEUZE, 1987, p. 04).

Não existe aprendiz que não seja 'egiptólogo' de alguma coisa. Alguém só se torna marceneiro tornando-se sensível aos signos da madeira, e médico tornando-se sensível aos signos da doença. A vocação é sempre uma predestinação com relação aos signos. Tudo que nos ensina alguma coisa emite signos. Tudo que nos ensina alguma coisa emite signos, todo ato de aprender é uma interpretação de signos ou de hieróglifos.(DELEUZE, 1987, p. 14)

O aprendiz é submetido a situações provocadas pelos impactos dos signos da arte, que o forçam buscar o sentido, quando sofre uma violência (DELEUZE, 1987). É como alguém que ao viajar para um país estrangeiro é constantemente violentado pelos signos deste mundo, e forçado a aprender as tarefas mais simples do cotidiano daquele país.

Ao ser bruscamente transportado para um novo ambiente, os hábitos anteriores não servem e o viajante vive sucessivas experiências de problematização. Não se trata de mera ignorância mas de estranhamento e tensão entre o saber anterior e a experiência presente.(KASTRUP, 2001, p. 17)

É nesse instante - do estranhamento - que as faculdades cognitivas dos sujeitos (estudantes) são mobilizadas para o ato de aprender: quando o professor, cria condições pela linguagem das artes para que o aluno faça seus próprios mapas com. Não há aí uma outra alternativa para ele: buscar compreender os signos por uma questão de sobrevivência.

Nessas circunstâncias, o processo de aprendizagem concebe-se na ação de interpretar, decifrar e explicar no encontro com os signos da arte (DELEUZE, 1987). Buscase por narrativas que possibilitem pensar sobre os signos dos mundos ou uma invenção de narrativas a partir deles. Aprender é inventar trajetórias, criar histórias, sempre com e sempre a partir de. 
Com base nessas proposições sobre espaço, lugar, cartografia e mapas e a linguagem da arte fotográfica, o título desse texto "Cartografia, mapa e fotografia: outra narrativa das serras turísticas capixabas no contexto da educação geográfica do IFES", talvez produza mais sentido para o leitor.

Em suma, o que se pretende é cartografar processos de criação de outras narrativas do espaço e lugar sobre a região serrana turística do Espírito Santo, a partir da linguagem da fotografia, mesmo dentro de um contexto de aprendizagem de um Instituto Federal de Educação como nos cursos técnicos integrados ao ensino médio.

2 Contextualização: possíveis processos de subjetivação pelas imagens de uma narrativa sobre o espaço e lugar

Nunca, aparentemente, a imagem - e o arquivo que conforma desde $o$ momento em que se multiplica, por muito pouco que seja, e que se deseja agrupá-la, entender sua multiplicidade - nunca a imagem se impôs com tanta força em nosso universo estético, técnico, cotidiano, político, histórico. Nunca mostrou tantas verdades tão cruas; nunca, sem dúvida, nos mentiu tanto solicitando nossa credulidade; nunca proliferou tanto e nunca sofreu tanta censura e destruição. (DIDI-HUBERMAN, 2012, p. 209)

Nessa citação, Didi-Huberman (2012) denuncia a subordinação dos sentidos das pessoas diante dessas imagens. Quando as imagens falam a verdade? Quando as imagens mentem? Que signos e narrativas escondem-se nas entrelinhas das imagens que violentam as pessoas todos os dias?

A partir dessa problematização, como processo para potencializar a força criadora do pensamento, propomos uma oficina "Portfólio de Imagens da Minha Cidade". Para tanto, a experimentação possibilitou o conhecimento dos tipos de imagens que são amplamente divulgadas pelos meios de comunicação local por meio de revistas, jornais impressos e sites. Que imagens bombardeiam os estudantes dessa região serrana turística do Espírito Santo todos os dias? 
Folheando revistas e jornais locais do município de Venda Nova do Imigrante (Figura 1), situado na região serrana do Espírito Santo, foi possível constatar uma grande diversidade de fotografias antigas que apresentam uma narrativa central e única: o pioneirismo, o sofrimento e a superação dos imigrantes italianos que ali chegaram no final do século XIX e início do século XX. Nomes de ruas, de bairros e de estabelecimentos comerciais fazem referências às famílias desses heróis pioneiros. Além disso, para divulgar e consolidar cada vez mais essa narrativa, as fotografias se constituem como um recurso muito usado pela imprensa local, como o Jornal Folha da Terra, a Revista Folha Nova e a Revista Folha da Polenta, todas pela editora Folha da Terra. As reportagens sempre contemplam a cultura italiana a partir de várias temáticas, como a história de ocupação, os costumes, as vestimentas, as manifestações religiosas e as mudanças paisagísticas e arquitetônicas dentro de uma perspectiva de “progresso e evolução".

Figura 1 - Mapa do município de Venda Nova do Imigrante (ES)

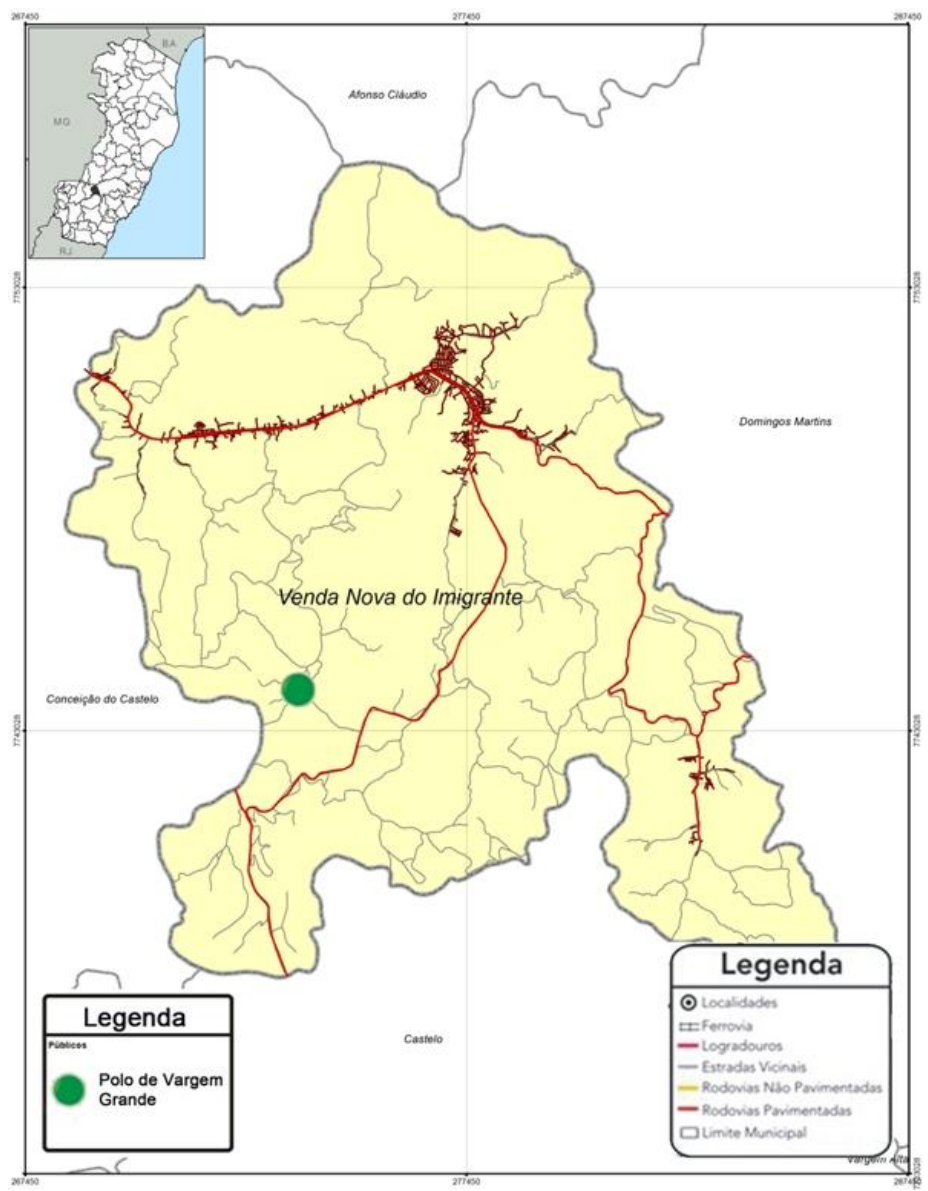

Disponível em https://sedes.es.gov.br/Media/sedes/Imagens\%20Municipios/mapa_polo_VNI.jpg Acesso em: 12/03/2018 
Ademais, as fotografias se adequam ao meio de distribuição de informações e propagações (FERRAZ, 2017, p. 67) dessa narrativa, como as revistas e jornais especiais (fotos 1, 2 e 3) distribuídos gratuitamente em uma grande festa tradicional que ocorre todos os anos na cidade, em dois finais de semana do mês de outubro, que atrai muitos turistas de várias partes do Brasil e, cujos recursos arrecadados, são repassados para o hospital do município e para outras obras sociais.

Foto 1 - Capas da Revista Folha da Polenta
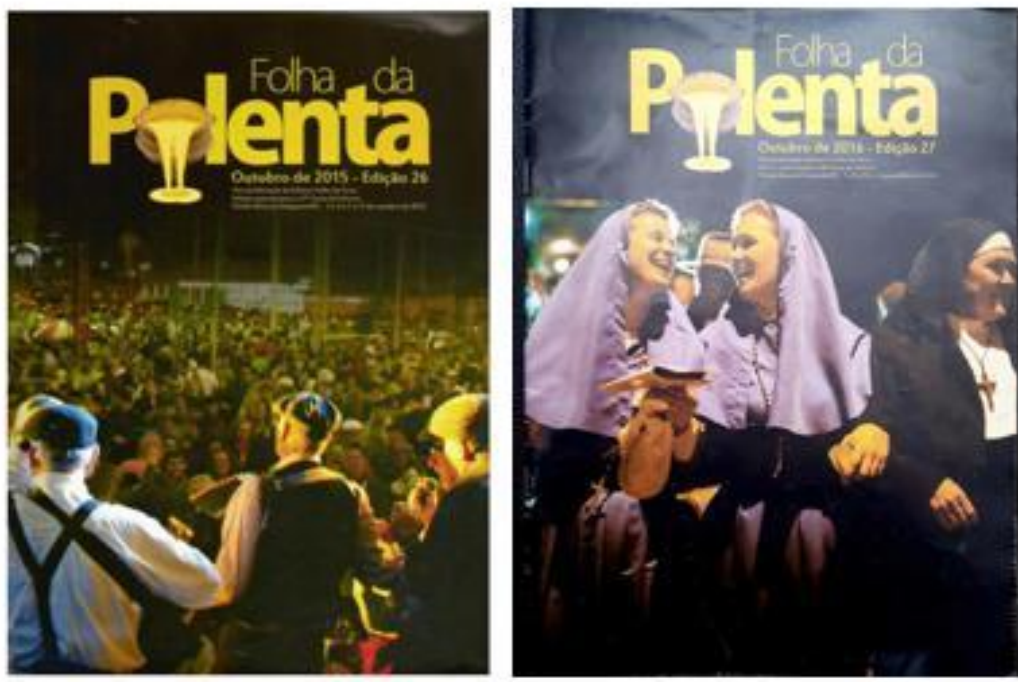

Fonte: Revista Folha da Polenta (2015) e (2016)

Foto 2 - Famílias tradicionais do município e suas vestimentas da época
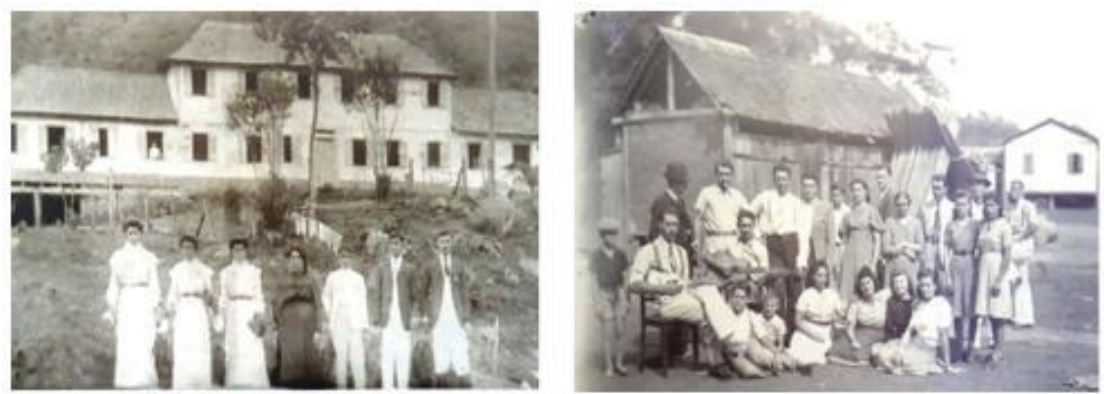

Fonte: Revista Folha da Polenta (2015) 
Foto 3 - Desfile nas ruas com roupas típicas
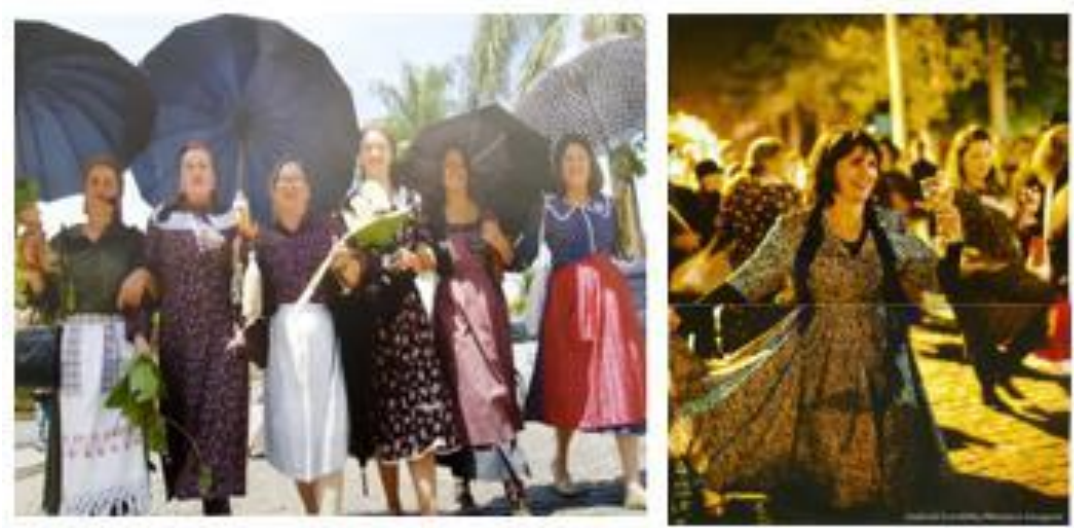

Revista Folha da Polenta (2015)

As fotografias são bem produzidas e chamam a atenção pela disposição das luzes, pela intensidade das cores e sempre apresentam pessoas sorridentes, dançando e vestidas com roupas típicas que lembram aquelas que foram usadas pelos antepassados europeus do final do século XIX e início do século XX. Há destaque também para a culinária italiana (polenta, massas, embutidos e vinhos) que é amplamente divulgada e vendida durante toda a festa.

A ampla massificação dessa narrativa por meio das fotografias possibilita a consolidação de uma cultura italiana também como mercadoria, em que as revistas, os jornais e os livros de memória são veículos de produção e reprodução de mercadorias culturais (GUATTARI; ROLNIK, 2013). Nesse caso, o conceito de cultura está fortemente ligado às atividades "padronizadas, instituídas [...] e capitalizadas para o modo de semiotização dominante - ou seja, elas são cortadas de suas realidades políticas" (GUATTARI, ROLNIK, 2013, p. 21). Processos de subjetivação que envolvem a dimensão cultural (GUATTARI; ROLNIK, 2013) que possivelmente reverberam na visão dos estudantes sobre a cidade, sobre o espaço e lugar. Porventura a educação geográfica encontra uma grande oportunidade para ser repensada dentro de um cenário marcado por um informal pensamento homogêneo.

O que possibilitou esse processo? Quiçá as ausências de outras narrativas que foram produzidas ainda no passado colonial do Brasil e que se perderam ou foram apagadas ao longo do tempo. O que se sabe é que antes da chegada dos imigrantes 
europeus em Venda Nova do Imigrante, Conceição do Castelo e o Distrito de Pedra Azul do Aracê (Domingos Martins) - municípios que formam a região serrana do Espírito Santo - eram ocupados por fazendas portuguesas que empregavam mão de obra escrava africana (JORNAL FOLHA DA TERRA, 1996).

Assim, há uma grande lacuna sobre o destino da população que foi escravizada (foto 4) após a assinatura da Lei Áurea, de 13 de maio de 1888:

libertou os escravos, mas deixou-os à margem do caminho, sem terra, sem trabalho, sem escolas, sem emprego, entregues à própria sorte. De que lhes adiantou a liberdade sem ter o que fazer, sem ter para onde ir? A maioria deles voltou à condição de escravos. (FALCHETTO, 2017, p. 25)

Foto 4 - Descendentes dos escravos que habitaram Venda Nova do migrante/ES
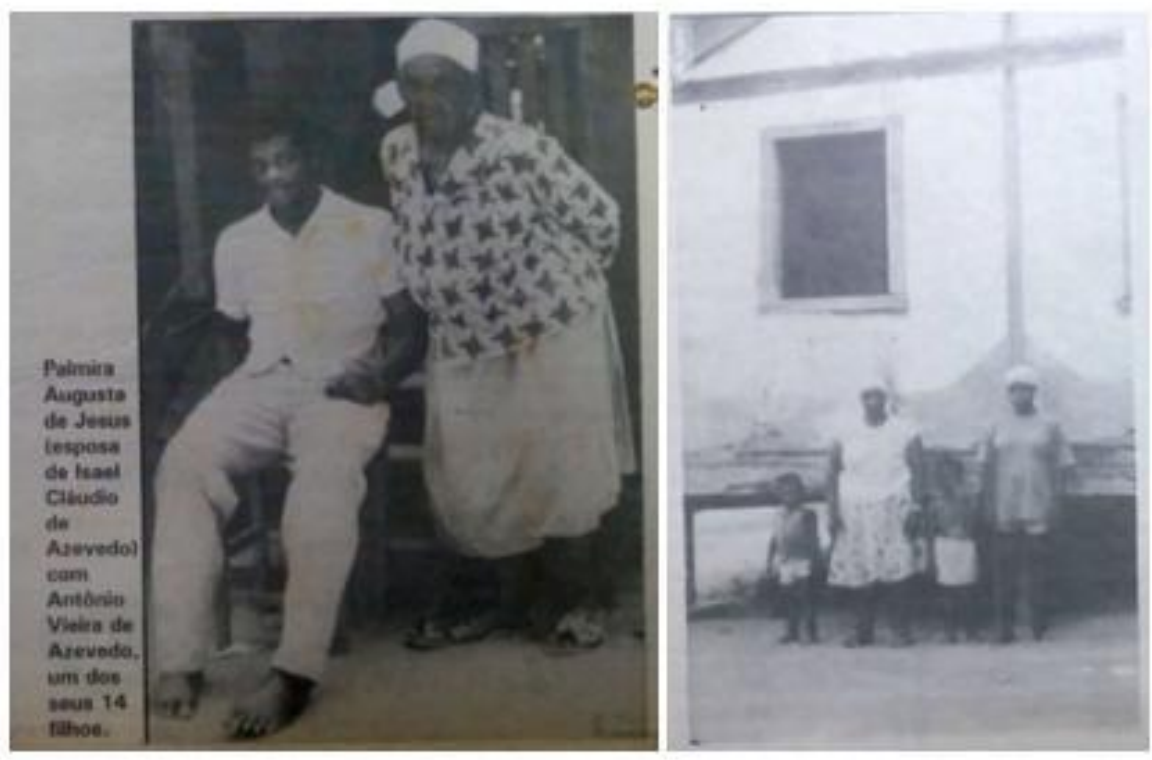

Fonte: Jornal Folha da Terra (1996) 
Foto 5 - Capa do livro de memórias dos afrodescendentes do município de Venda Nova do Imigrante/ES

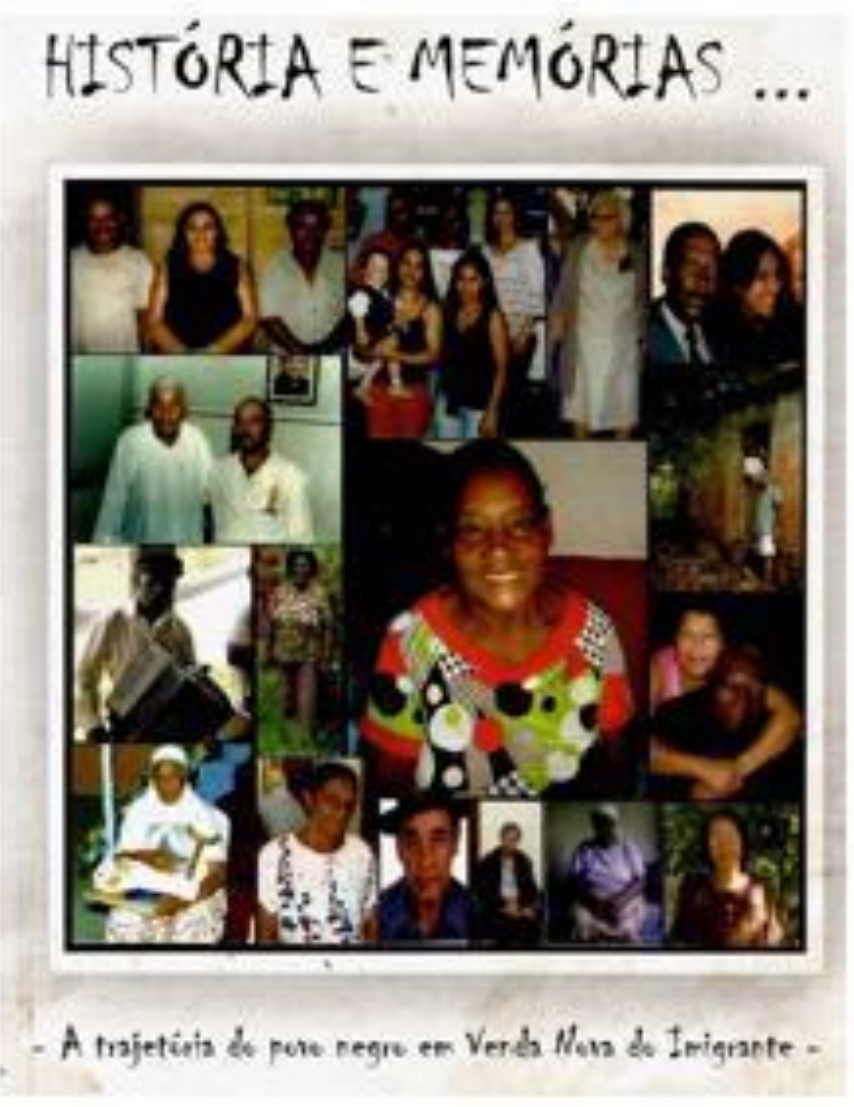

Fonte: MOREIRA, 2010

Diante dessa realidade, houve um exemplo de tentativa de resgatar a narrativa do povo africano e de seus descendentes nessa região. Foram publicados 200 exemplares do livro "Histórias e Memórias: a trajetória do povo negro em Venda Nova do Imigrante" (foto 5), uma coletânea de depoimentos e fotos de afrodescendentes, de famílias tradicionais da região, organizada pela historiadora Célia Januário Moreira (2010), em parceria com os estudantes do terceiro ano do ensino médio de uma escola pública estadual. Uma maneira de fortalecer, de trazer à luz cenas, práticas e políticas pouco aparentes ao que é ofuscado (WUNDER, 2011, p. 166) pela grande variedade de imagens fotográficas que destacam a cultura dos imigrantes italianos.

A mesma ausência também ocorre em relação à presença dos indígenas na região. Nas publicações locais existe apenas a menção de que algumas formações rochosas e nomes de regiões receberam toponímias de origem indígena, apesar de alguns 
documentos históricos apontarem a existência de dois aldeamentos que aprisionaram, disciplinaram e escravizavam os índios Puris, em Domingos Martins e Conceição do Castelo (FONTAN, 1998). Sobram apenas relatos de artefatos antigos (foto 6) que foram encontrados pelos descendentes de italianos em suas propriedades e que foram expostos em um museu da cidade (JORNAL FOLHA DA TERRA, 1996).

Foto 6 - Exibição de artefatos que "supostamente" evidenciam a presença dos povos indígenas antes da chegada dos imigrantes
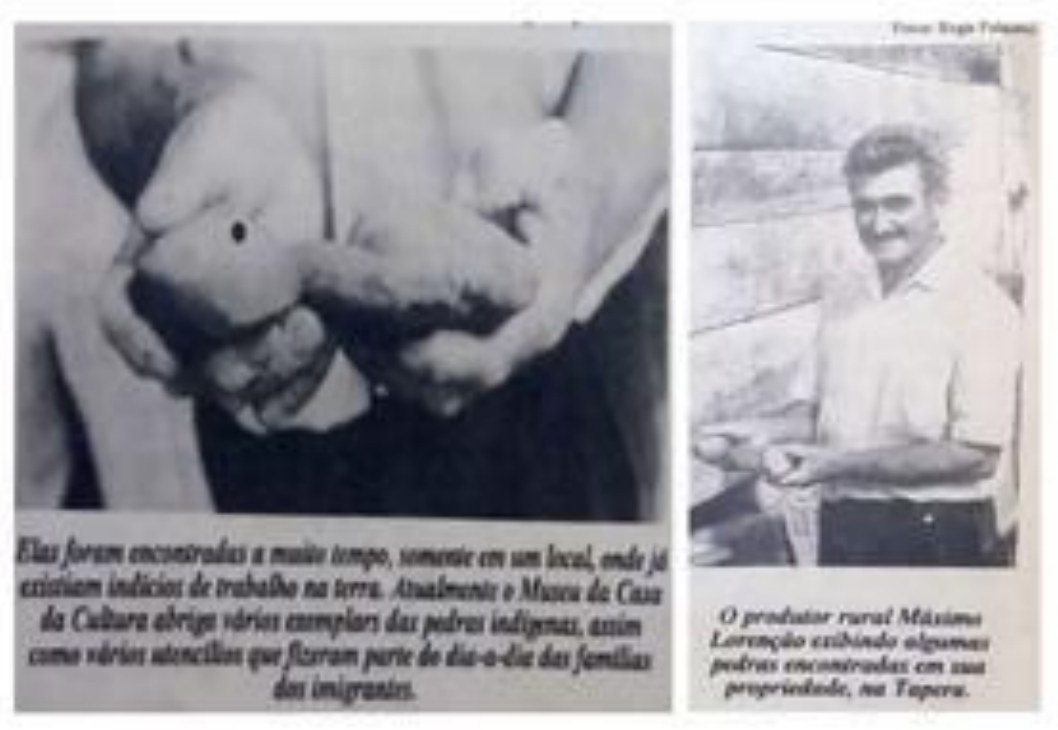

Jornal Folha da Terra (1996)

Esse é o contexto em que os estudantes dos cursos técnicos do Instituto Federal de Educação do Espírito Santo estão inseridos. Eles vivenciam esses processos de subjetivação todos os dias, o que justifica a urgência em buscar condições favoráveis para a expressão de outras visibilidades, de outros sentidos a partir das linguagens das artes (WUNDER, 2011).

Dentro desse contexto,

as escolas e as salas de aula são ambientes sociais complexos em que interagem, de várias maneiras, grupos de pessoas que têm suas histórias pessoais, identidades, personalidades, crenças, valores, interesses e experiências. Estas características afetam naturalmente o ensino e a aprendizagem, pois a maioria das ações desses indivíduos é determinada pelo passado, gênero, idade e etnia, que têm um papel a desempenhar 
na maneira como o professor conduz o seu trabalho na escola. (MOREIRA; CALEFFE, 2008, p. 11)

A ideia é ir além do discurso único que permeia as fotografias publicadas repetidas vezes pelos meios de comunicação. É tornar a escola uma arena ideal para a luta da subjetivação singular contra os processos de subjetivação coletiva. É permitir que o estudante se afaste da ideia de que as fotografias são "provas visuais da existência das coisas - dos lugares - no mundo" (OLIVEIRA JR., 2009, p. 10), uma vez que essa escola atende alunos de outros municípios da região serrana do Espírito Santo, os quais, trazem consigo outras narrativas, outros pensamentos sobre o espaço e lugar.

\title{
3 Imagens e outras narrativas através da linguagem da arte
}

\author{
“Nossas digitais não se apagam nas vidas que tocamos. \\ [...] Ficando aqui o dia inteiro, ou vivendo desde quando a gente nasceu \\ ou não. \\ [...] Essa visão única que a gente tem da nossa cidade, compõe para uma \\ imagem geral"
}

(Alunas do $2^{\circ}$ ano, técnico de administração, IFES, 2016)

Cabe agora apresentar a oficina "Portfólio de imagens da minha cidade", desenvolvida com os alunos do $2^{\circ}$ ano do curso técnico integrado ao ensino médio de administração do Instituto Federal de Educação. Era o final do ano letivo de 2016. O trabalho consistia em apresentar a cidade onde os estudantes moravam apenas por uma coleção de fotografias. Ficaram livres para usar qualquer fonte, fosse ela digital ou impressa. Os estudantes também deveriam tirar suas próprias fotografias de qualquer parte da cidade, de pessoas ou coisas que considerassem importantes. O tema que orientou os trabalhos dos alunos foi: "O espaço urbano do mundo contemporâneo" (SENE; MOREIRA, 2013). Também, foram orientados a não utilizarem o livro didático como fonte de pesquisa. 
Os processos de seleção, produção e ordenamento das imagens duraram aproximadamente quatro tempos de aulas de 50 minutos, dentro do laboratório de Informática, além dos momentos extraclasses para a produção das fotografias. Após esse processo, os trabalhos foram apresentados dentro do Laboratório de Cartografia Geográfica e Gestão Socioambiental, onde as carteiras foram dispostas em dois semicírculos; havia um computador conectado à internet, com projetor e TV de 42 polegadas à disposição. Somente após um sorteio prévio da apresentação, as imagens das cidades de Conceição do Castelo, Afonso Cláudio e Venda Nova do Imigrante perfilaram-se pelo telão e pela televisão.

Havia uma disputa entre os grupos. Parecia que os estudantes queriam mostrar qual cidade tinha mais atrativos para receber os turistas. Praças, Igrejas, jardins, avenidas principais, montanhas e monumentos foram apresentados. Todas as fotografias pesquisadas eram da internet e se repetiam exaustivamente entre os trabalhos. Enquadramentos, panorâmicas e seleção daquilo que seria mostrado eram cópias fiéis, disponíveis na internet, especificamente por meio do buscador de imagens da empresa Google ${ }^{\circledR}$ (foto 7).

Foto 7 - Imagens usadas a partir do buscador na internet.

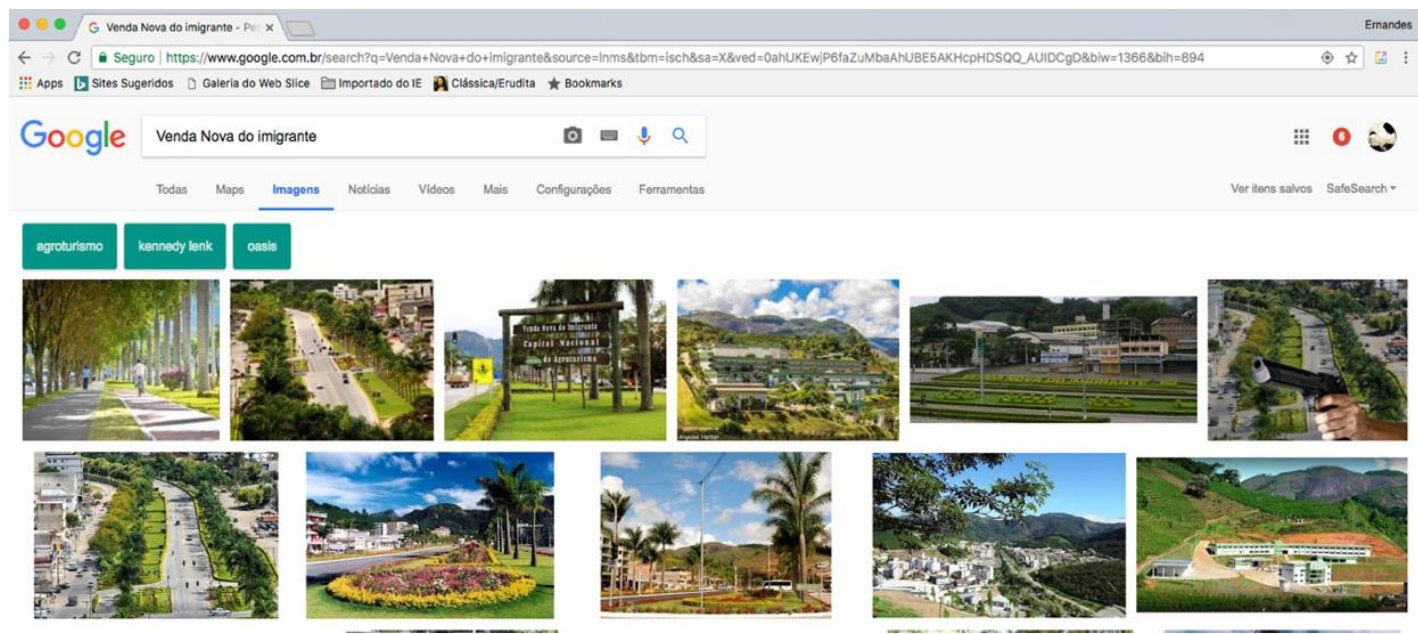

Disponível em www.google.com.br Acesso em: outubro de 2016

Foi possível constatar que as imagens selecionadas tinham o caráter documental em situações que poderiam ser vistas no cotidiano (OLIVEIRA JR., 2009, p. 15). A escola e os estudantes são bombardeados por essas imagens, que não são questionadas: quem as 
fotografou? Qual era a intenção do autor daquela fotografia? As imagens da internet intensificaram o processo de despolitização das mesmas, enfatizando a beleza, a paisagem-mercadoria, o lugar-mercadoria e o espaço-mercadoria. Isso se dá porque:

A imagem em mídia digital, é herdeira de uma tradição visual, que irá influenciar os seus possíveis usos e interpretações. Basta verificar o emprego freqüentemente dado às máquinas fotográficas e videográficas digitais: registro de coisas e eventos cotidianos voltados a servirem de suporte da memória. (PARRA, 2011, p. 182)

Dessa forma, na sociedade atual constantemente conectada pela internet, tornase difícil libertar-se do poder influenciador dessas imagens. Elas naturalizam-se a ponto de aparecerem de forma espontânea nos trabalhos dos estudantes do ensino básico. De forma sutil e efetiva,

estas imagens estão a gafar em nós pensamentos sobre o espaço geográfico. Impregnados no visual, nos chegam também sentidos para estes lugares, maneiras de significações uns em relação aos outros, propondo-nos raciocínios e imaginações acerca de cada um deles e das relações que existem entre eles. (OLIVEIRA JR., 2009, p. 10)

Essas imagens agenciam as subjetividades dos alunos e professores. Determinam até mesmo os enquadramentos, o que deve ser incluído ou excluído na fotografia. Educam o olhar no sentido de serem aceitas incondicionalmente. Delimitam a maneira de mapear os espaços e lugares como processos de decalques. Sem vida, sem movimento, sem conflitos, sem política, como se fossem estátuas que glorificam a máxima verdade do mundo contemporâneo, essas imagens "acabam funcionando como um dispositivo de interpretação e, ao mesmo tempo, de produção de legitimidade” (PARRA, 2011, p. 187).

Entretanto, o trabalho de duas estudantes causou certa inquietação. Elas trouxeram imagens (foto 08) que eram diferentes de tudo que foi visto até aquele momento. Além de suas próprias fotografias, havia dois textos, um lido em voz alta, retirado do filme chamado "Lembranças" (2010), com atuação de Robert Pattinson, 
Cartografia, mapa e fotografia: outra narrativa das serras turísticas capixabas no contexto da educação geográfica do IFES

dirigido por Allen Couter e escrito por Will Fetters, um drama que trata de perdas familiares ligadas ao suicídio, e outro posto nas legendas, criando um ambiente bem dramático e reflexivo. Alguns estudantes, nativos da cidade de Venda Nova do Imigrante, não reconheceram os lugares fotografados, porque esses espaços revestiram-se de outros significados. Enquadramentos que não aparecem na internet, mas causaram estranheza e mobilizaram os pensamentos dos discentes sobre o espaço e o lugar.

Foto 8 - Sequência de imagens da apresentação das estudantes sobre a cidade
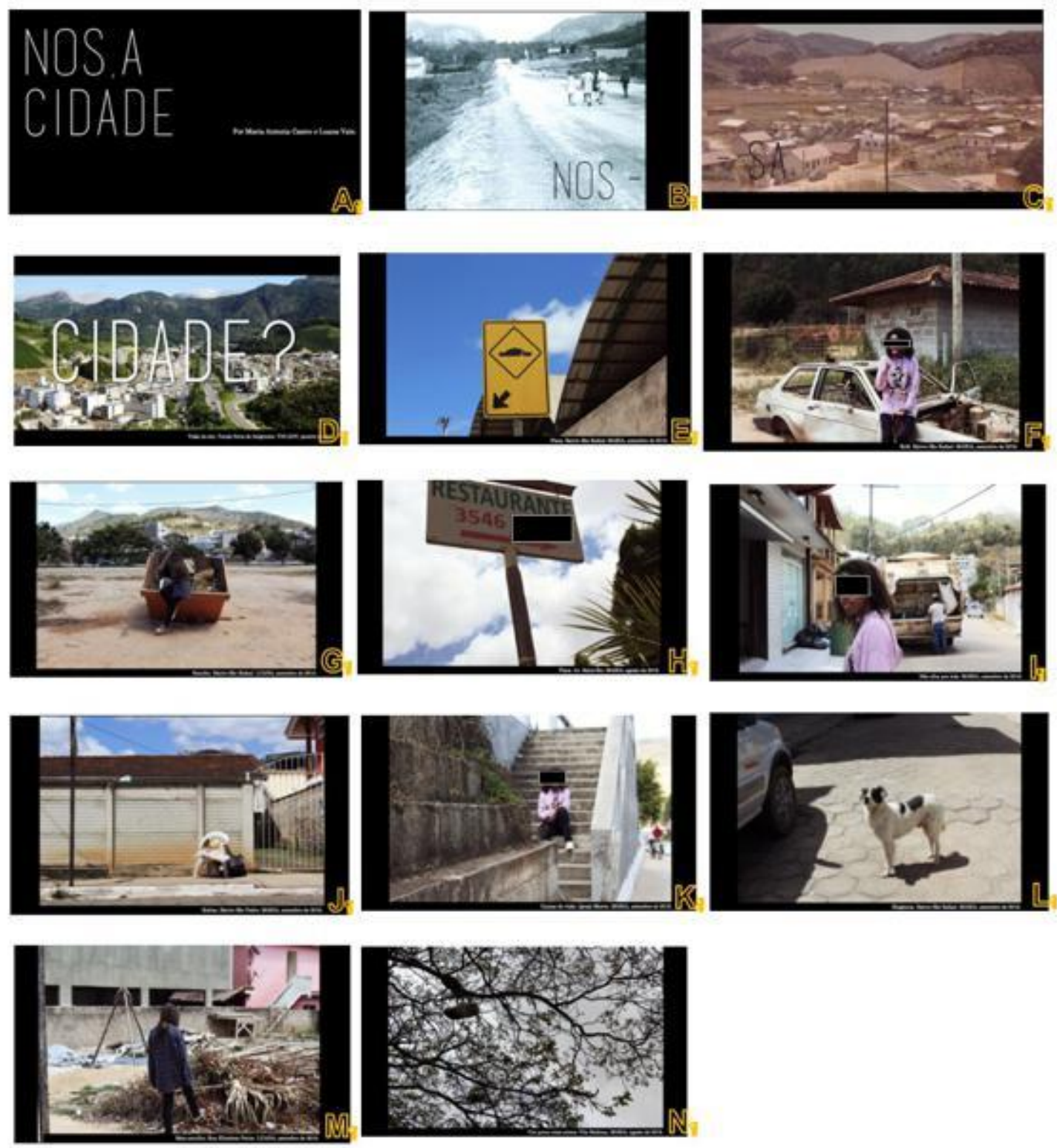

Fonte: Fotografias produzidas pelas estudantes durante a Oficina "Portfólio de Imagens da minha cidade" (2016) 
O título também foi desafiador “Nos, a cidade, Nos-sa, cidade?” Que remete pensar em muitos sentidos. As duas estudantes ressaltaram sua condição de estrangeiras naquela cidade, onde cada imagem revelava detalhes de um cotidiano, que não invisível pelos meios de comunicações. "Nos" também remete ao pensamento dos "nós" que ainda precisam ser desatados na cidade. A composição das fotos criou outras narrativas sobre a cidade. Outras maneiras de contar a sua história e de pensar sobre o espaço.

Essa estratégia, intuitiva, ao modo de ver desse professor-pesquisador e também estrangeiro, está intimamente ligada às

fábulas as/com/através das fotografas [que] seria, sobretudo, experimentar outras possibilidades do pensamento que não negam as formas já instituídas de pensar as fotos, mas sim fazem derivar esse pensar instituído para outras possíveis imaginações da realidade geográfica a que nos remetem as fotografias. (OLIVEIRA JR.; SOARES, 2012, p. 116)

Os closes, os sorrisos, o flagrante do cachorro, o lixo e o muro, a escadaria da famosa igreja central de São Pedro provocaram as imaginações dos estudantes que assistiam à apresentação. Nem mesmo os textos lidos foram reconhecidos por aqueles que assistiram ao filme. As fotografias movimentaram o pensamento pelo encontro delas com os outros estudantes (WUNDER, 2011). Despertaram indagações: "que cidade é essa?" É a mesma pela qual cada estudante passa todos os dias quando sai de sua casa e se dirige para a escola. Eles não reconheceram esse lugar. Brotaram em suas mentes cidades imaginárias, lugares abstratos que por breves instantes, durante aquela apresentação, fizeram com que se libertassem das amarras da subjetivação dos meios de comunicação ancorados por políticas econômicas ligadas ao capitalismo. Por breves momentos, o professor-estrangeiro renovou suas esperanças de que a linguagem da arte também pode criar micropolíticas, que pode elevar os estudantes dos cursos técnicos para além daquilo que é dado, posto e imposto pelas regulamentações, pelo currículo endurecido, pela necessidade de formar técnicos, que simplesmente, reproduzem comportamentos na sociedade. 
As estudantes não fizeram questão de explicar o que era cada fotografia. Deixaram que a plateia fizesse esse trabalho. Os signos da arte provocaram 0 pensamento da turma para a essência máxima da diferença (DELEUZE, 1987). As autoras das fotografias apenas afirmaram que não houve um roteiro e que a necessidade de tirar as fotos foi surgindo durante as caminhadas. A máquina estava sempre preparada para o devir.

As cenas não representavam o congelamento de um instante, não eram apenas registros de memórias, constituíam “obras de uma linguagem, da linguagem fotográfica, que poderia ser arrastada a potencialidade mais ampla se tomada como força expressiva - fabuladora - de novos pensamentos" (OLIVEIRA JR.; SOARES, 2012, p. 116). Essa é a potência e não no encadeamento de assuntos e imagens, porque o que se quer é que o estudante passeie pelas possibilidades de criar ficções (MARQUES; SGOBIN, 2014).

Ao final da apresentação, após esse turbilhão de ondas de pensamentos dirigido pela imaginação e provocado pelas fotografias, ocorreu o silêncio. Os estudantes olhavam para o professor e se perguntavam se o que viam era o certo. Silêncio que foi interrompido pelas palmas, puxadas pelo professor, e que foi seguido por muitas indagações por parte dos alunos. A arte cumpriu o seu papel: o de mobilizar os pensamentos sobre o espaço e lugar para além das imagens-clichês.

\section{Considerações Finais}

Cidades turísticas como essas que foram apresentadas são reféns de uma maneira de pensar. São obrigadas a se estruturar no sentido de receber os turistas; não somente dentro de uma perspectiva física e econômica, mas também no âmbito das ideias, no campo das narrativas.

Nesse sentido, os jornais, revistas, rádios e TVs locais necessitam criar uma narrativa coerente e, principalmente, mediada pelas imagens, devido ao grande poder agenciador que elas possuem (HOLLMAN, 2014). Realizam apagamentos de outras histórias que à maneira de ver dos mercados não trazem consigo uma estética atraente, como as narrativas provenientes dos povos indígenas Puris e dos povos negros que 
habitaram, trabalharam e constituíram os espaços que compõem atualmente esses lugares. Condição que dificulta pensar os lugares como uma coleção de múltiplas trajetórias diferentes que se atravessam (MASSEY, 2015). Tal situação, como afirma a epígrafe proveniente dos relatos das alunas, gera uma narrativa única que determina a imagem geral sobre o lugar nas mentes daqueles que nasceram, cresceram e habitaram a região.

As imagens amplamente difundidas pelas revistas e jornais locais, produzem esta narrativa: o pioneirismo, o sofrimento e a superação do imigrante italiano. Ao deparar-se com essas imagens e com a repetição delas, dúvidas emergem: e as narrativas dos povos indígenas? O que aconteceu com os povos negros após a abolição da escravatura? Perguntas que nasceram de grandes lacunas que estão presentes nos documentos impressos até então analisados. Cabem outras histórias e outras trajetórias?

Nesse sentido, os estudantes estão imersos nesse universo imagético único e ainda no contexto técnico profissionalizante que, na sua essência, é constituído por padrões que devem ser assimilados pelos estudantes e reproduzidos no mercado de trabalho. Como fugir desses processos de subjetivação? Como criar ambientes e contextos de emancipação nessa modalidade de educação?

Como tese de que as linguagens das artes propiciam aos estudantes a elaboração de mapas e não decalques (DELEUZE; GUATTARI, 2011a), nasceu a ideia de implementar essa Oficina de "Portfólios de Imagens da minha cidade". A princípio, para verificar como os processos de subjetivação estão entranhados no modo de ver o mundo, os estudantes e, em seguida, como uma maneira de oportunizar outras possíveis narrativas sobre o espaço e o lugar.

Durante o processo de elaboração (seleção, produção e composição) e apresentação dos resultados, foi possível constatar como as narrativas externas que exortam os aspectos turísticos, bem como a visão da fotografia como repositório de imagens estão presentes na maneira de ver o espaço e lugar dos estudantes.

Dessa forma, a arte da fotografia permitiu também ver que os processos de subjetivação podem ser subvertidos, podem ser quebrados, podem ser ultrapassados. 0 
trabalho "Nos, a cidade, Nós e a cidade?" provocou o silêncio, a desordem, outras narrativas, outras possibilidades de geografias. O pensamento aflorou instantes de reflexão que fizeram os alunos imaginarem que aquelas fotografias se relacionavam com outras cidades, imaginárias. Nesse momento, a linguagem da arte fotográfica agenciou um comportamento semelhante ao dos artistas poetas, por exemplo. A fotografia deixou de ser apenas um registro em um papel sem vida para se transformar em

\begin{abstract}
um resto que contém uma potência de criação de sentidos ao mesmo tempo corpóreos e incorpóreos, sentidos que vivem e morrem entre a intenção de deixar marcas e a imprevisibilidade que se faz pela própria linguagem fotográfica. No ato de pensar por fotografias, escorregar por esse entre-lugar, um entre indefinido que gera o acontecimento como quase, como força indizível - o sentido último que nunca se alcança - e no padecer da impossibilidade, quem sabe, palavras outras, sentidos outros. Focar esse justo desequilíbrio, essa pulsação vibrátil que não nos possibilita dizer onde está a linha que separa uma coisa e outra, numa criação de sentidos que se faz entre a finitude e a infinitude do tempo. Quase morte, fio de vida e pulsar. (WUNDER, 2011, p. 171, grifo da autora)
\end{abstract}

Esse agenciamento entre a ciência geográfica e a linguagem fotográfica como arte é que pode mover o tipo de pensamento sobre o espaço e lugar para além do livro didático. É a aposta dessa pesquisa. De criar situações para uma educação geográfica por rizomas. Por infinitas possibilidades de conexões. De ampliar a ideia sobre a cidade, sobre a urbanização incluindo a experiência do corpo, como foi para as estudantes que posaram diante das suas fotografias em lugares e detalhes incomuns para o senso comum.

Possivelmente seja essa a saída para que a educação geográfica crie situações em que mais subjetividades individuais sejam estabelecidas, para que outras possiblidades de geografias sejam geradas, mais alinhadas à perspectiva da criatividade, de criação de problemas, além da simples resposta dos já existentes. Sempre no sentido de mobilizar todas as faculdades da inteligência e da imaginação do ser humano, que é responsável pela sua consolidação como ser que também faz parte da natureza como criação e cocriador. 


\section{Referências}

ADÃO, Edilson; FURQUIM JR., Laercio. Geografia em rede. São Paulo: Editora FTD, 2013. V.1, $288 \mathrm{p}$.

BARROS, Laura Pozzana; KASTRUP, Virgínia. Cartografar é acompanhar processos. In.: PASSOS, E.; KASTRUP, V.; ESCÓSSIA, L. (Orgs.). Pistas do Método de Cartografia: pesquisa-intervenção e produção de subjetividade. 4.ed. Porto Alegre: Editora Sulina, 2015. $207 \mathrm{p}$.

BAUMAN, Zigmunt. Modernidade líquida. Rio de Janeiro: Editora Zahar, 2001.

CASTELLAR, Sonia Vanzella. A cartografia e a construção do conhecimento em contexto escolar. In.: ALMEIDA, Rosângela Doin (org). Novos rumos da cartografia escolar: currículo, linguagem e tecnologia. São Paulo: Editora Contexto, 2011. 192 p.

DELEUZE, Guilles. Proust e os signos. Traduzido por A. C. Piquet e R. Machado. Rio de Janeiro: Editora Graal, 1987.183 p.

DELEUZE, Guilles. Crítica e clínica. 2.ed. Traduzido por Peter Pál Pelbart. São Paulo: Editora 34, 2013. 204 p.

DELEUZE, Gilles; GUATTARI, Félix. Mil platôs: capitalismo e esquizofrenia 2. Tradução de Ana Lúcia de Oliveira, Aurélio Guerra Neto e Celia Pinto Costa. São Paulo: Editora 34, 2011. v. 1, 128 p.

DELEUZE, Gilles; GUATTARI, Félix. Mil platôs: capitalismo e esquizofrenia 2. ed.Tradução de Ana Lúcia de Oliveira e Lúcia Cláudia Leão. São Paulo: Editora 34, 2011a. v. 2, 128p.

DIDI-HUBERMAN, Georges. Quando as imagens tocam o real. Pós. Belo Horizonte, v. 02, n.04, p.204-219, novembro de 2012.

FALCHETTO, Benjamim. 0 tesouro escondido. Venda Nova do Imigrante, ES: Edição do autor, 2017. $216 \mathrm{p}$.

FERRAZ, Cláudio Benito O. Arte, imagem e geografia: desafios e temores para o pensar. In.: NUNES, Flaviana Gasparotti, NOVAES, Ínia Franco de (orgs.). Encontros, derivas, rasuras: potências das imagens na educação geográfica. Uberlândia: Editora Assis, 2017. $264 p$.

FONTAN, José Coco. Conceição do Castelo: elementos da história. Vitória: s.n., 1998. 
GIRARDI, Gisele. Mapas alternativos e educação geográfica. Revista Percursos, Florianópolis, v. 13, n. 02, p. 39-51.jul/dez, 2012.

GUATTARI, Félix; ROLNIK, Suely. Micropolítica: cartografias do desejo. 12. ed. Petrópolis: Editora Vozes, 2013. 440 p.

HOLLMAN, Verônica. Regimes visuais da questão ambiental nos livros didáticos de geografia na Argentina. Revista Brasileira de Educação em Geografia, Campinas, v. 4, n.8, p. 221-240, jul/dez., 2014.

JOLY, Fernand. A cartografia. 10. ed. tradução de Tânia Pellegrini. Campinas: Editora Papirus, 2007. 135p.

JORNAL FOLHA DA TERRA. Projeto conhecendo Venda Nova do Imigrante (ES). Venda Nova do Imigrante, ES: Editora Folha da Terra, 1996.

KASTRUP, Virgínia. Aprendizagem, arte e invenção. Psicologia em Estudo, Maringá, v.6, n.1, p.17-27, 2001.

MARQUES, Ivânia; SGOBIN, Alexsandro. Entre imagens. Revista Geografares, p. 182-192, janeiro-agosto, 2014. Edição especial.

MASSEY, Doreen. Pelo espaço: uma nova política da espacialidade. 5. ed. Tradução de Hilda Pareto Maciel e Rogério Haesbaert. Rio de Janeiro: Editora Bertrand Brasil, 2015. $314 \mathrm{p}$.

MOREIRA, Celina Januário (Orgs.). História e memórias: a trajetória do povo negro em Venda Nova do Imigrante. Venda Nova do Imigrante, ES: Edição da Prefeitura Municipal de Venda Nova do Imigrante (PMVNI), 2010. 183p.

MOREIRA, Herivelto; CALEFFE, Luiz Gonzaga. Metodologia da pesquisa para o professor pesquisador. 2. ed. Rio de Janeiro: Editora Lamparina, 2008. 246 p.

OLIVEIRA JR., Wenceslao Machado de. Fotos em sites: geografia da cultura contemporânea. Revista Geografares, n. 07, 2009.

OLIVEIRA JR., Wenceslao Machado de; SOARES, Elaine dos Santos. Fotografias didáticas e geografia escolar entre evidência e fabulações. Revista Percursos, Florianópolis, v.13, n.02, p. 114-133, jul/Dez, 2012. 
PARRA, Henrique Z. M. Conhecimento e imagem: crítica informacional entre o visível e o invisível. In.: AMORIM, Antônio Carlos; GALLO, Sylvio; OLIVEIRA JR., Wenceslao Machado de (Orgs.) Deleuze e imagem e pensamento... Petrópolis, RJ: De Petrus; Brasília, DF: CNPq, 2011.

REVISTA FOLHA DA POLENTA, edição 26 para a $37^{\circ}$ Festa da Polenta. Venda Nova do Imigrantes, ES: Editora Folha da Terra, outubro de 2015.

REVISTA FOLHA DA POLENTA, edição 27 para a $38^{\circ}$ Festa da Polenta. Venda Nova do Imigrantes, ES: Editora Folha da Terra, outubro de 2016.

SEDES. Secretaria de Estado de desenvolvimento do Espírito Santo. Mapa do Município de Venda Nova do Imigrante, ES. Disponível em: https://sedes.es.gov.br/Media/sedes/

Imagens\%20Municipios/mapa_polo_VNI.jpg. Acesso em: 12 mar. 2018.

SENE, Eustáquio de; MOREIRA, João Carlos. Geografia geral e do Brasil: espaço geográfico e globalização. 2. ed. São Paulo: Editora Scipione, 2013. v. 1, 246p.

WUNDER, Alik. Fotografias, restos quase mortais. In.: AMORIM, Antônio Carlos; ; GALLO, Silvio; OLIVEIRA JR., Wenceslao Machado de (Orgs.). Conexões: Deleuze e imagem e pensamento e.... Petrópolis: Editora De Petrus; Brasília, DF: CNPq, 2011. 232p.

Recebido em: 06/06/2018

Aprovado em: 06/11/2018

Universidade do Estado de Santa Catarina - UDESC Centro de Ciências Humanas e da Educação - FAED

Revista PerCursos

Volume 19 - Número 41 - Ano 2018 revistapercursos@gmail.com 